\title{
CORRELATION OF SERUM SODIUM WITH SEVERITY OF HEPATIC ENCEPHALOPATHY
}

\author{
Muhammad Arshad ${ }^{1}$, Shah Zeb ${ }^{1}$, Muhammad Atif Tauseef ${ }^{1}$, Najeeb Ullah ${ }^{2}$ \\ 1. Naseer Teaching Hospital \\ 2. People Primary Healthcare Initiative, Noshehra
}

\begin{abstract}
INTRODUCTION

Hepatic encephalopathy (HE) is neuropsychiatric syndrome for which symptoms, manifested on a continuum, is deterioration in mental status, with psychomotor dysfunction, impaired memory, increase reaction time, poor concentration, disorientation, and in severe form coma and may develop at an annual rate of $8 \%$ in cirrhotic patients in Far Eastern studies. Fluctuation in serum sodium level is a frequent complication of advanced cirrhosis related to impairment in the renal capacity to eliminate solute-free water that causes retention of water that is disproportionate to the retention of sodium, thus causing a reduction in serum sodium concentration and hypo-osmolality. Hyponatremia is a common finding in patients with decompensated cirrhosis due to an abnormal regulation of body fluid homeostasis.
\end{abstract}

\section{OBJECTIVE}

To determine the correlation of serum sodium with severity of hepatic encephalopathy

\section{MATERIAL AND METHODS}

This study was conducted at Naseer Teaching Hospital Peshawar. Duration of the study was 01 year and the study design was cross sectional (Correlation) study in which a total of 408 patients were observed by using - 0.1411 of correlation coefficient between serum sodium and hepatic encephalopathy $95 \%$ confidence level and $80 \%$ power of test. More over non probability consecutive sampling was used for sample collection.

\section{RESULTS}

In this study mean age was 65 years with $S D \pm 0.315$. Sixty two percent patients were male and $38 \%$ patients were female. Mean serum sodium level was $123 \mathrm{meq} / \mathrm{L}$ with $S D \pm 0.21$. Five percent patients had severity of grade I, 39\% patients had severity of grade II, $48 \%$ patients had severity of grade III and $8 \%$ patients had severity of grade IV. Correlation of severity of hepatic encephalopathy with serum sodium level was analyzed as all the 20 patients with severity of grade I had serum sodium level ranged 131-133 meq/L. All the 159 patients with severity of grade II had serum sodium level ranged 126-130 meq/L. In 196 patients with severity of grade III, 45 patients had serum sodium level ranged 126-130 meq/L while 151 patients had serum sodium level ranged 120-125 meq/L where as all the 33 patients with severity of grade IV had serum sodium level ranged 120-125 meq/L.

\section{CONCLUSION}

Hyponatremia was a common feature in patients with cirrhosis and its severity increased with the severity of liver disease. The existence of serum sodium concentration $<135 \mathrm{mmol} / \mathrm{L}$ was associated with greater frequency of hepatic encephalopathy. It was also noticed that more severe the hyponatremia, greater will be the grade of hepatic encephalopathy. Close monitoring of serum sodium concentration should be performed in patients with cirrhosis in order to prevent the rapid development of cirrhosis related complications.

KEY WORDS: Hepatic encephalopathy, frequency, cirrhosis, Spontaneous bacterial peritonitis. within 5-30

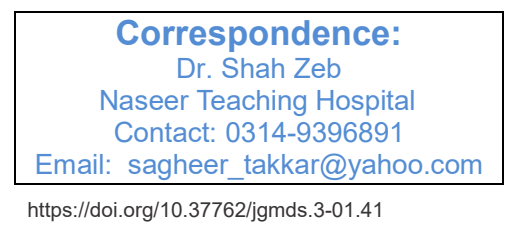




\section{INTRODUCTION}

Cirrhosis is a serious and irreversible disease. It is a major cause of mortality and morbidity worldwide. It is also a common cause of mortality amongst Pakistani population and frequent cause of admission in our hospitals. Cirrhosis develops in about $10-20 \%$ years. The most common cause being viral hepatitis as compared to West where alcohol is more common. ${ }^{1}$ Hepatic encephalopathy $(\mathrm{HE})$ is neuropsychiatric syndrome for which symptoms, manifested on a continuum, is deterioration in mental status, with psychomotor dysfunction, impaired memory, increase reaction time, poor concentration, disorientation, and in severe form $\mathrm{coma}^{2}$ and may develop at an annual rate of $8 \%$ in cirrhotic patients in Far Eastern studies ${ }^{3}$. Previous HE and cognitive dysfunction are associated with worse employment, financial status, and caregiver burden. Cirrhosis-related expenses impact the family unit's daily functioning and medical adherence. A multidisciplinary approach to address this burden is required. ${ }^{4}$ The clinical diagnosis of overt hepatic encephalopathy is based on two concurrent types of symptoms: impaired mental status, as defined by Conn's score (also called West Haven criteria) (on scale from 0 to 4, with greater score indicating more severe impairment), ${ }^{5}$ and impaired neuromotor function. ${ }^{2}$ Fluctuation in serum sodium level is a frequent complication of advanced cirrhosis related to impairment in the renal capacity to eliminate solute-free water that causes retention of water that is disproportionate to the retention of sodium, thus causing a reduction in serum sodium concentration and hypo-osmolality ${ }^{6}$. Hyponatremia is a common finding in patients with decompensated cirrhosis due to an abnormal regulation of body fluid homeostasis ${ }^{7}$. In patients without liver disease, low serum sodium is primarily associated with a broad variety of neurological manifestations related to the existence of brain edema, such as headache, disorientation, confusion, focal neurological deficits, seizures, and, in some cases, death due to cerebral herniation ${ }^{7}$. Severity of neurological symptoms in patients with low serum sodium correlates roughly with the levels of osmolality and sodium in the extracellular fluid. However, rather than the absolute reduction in serum sodium levels, the most important factor in determining the severity of neurological symptoms is the rate of fall in serum sodium levels, patients with acute hyponatremia having a much higher incidence of neurological symptoms than patients with chronic hyponatremia ${ }^{6}$.

Literature review suggested an association between serum sodium concentration and hepatic encephalopathy that serum sodium and serum ammonia concentrations have been the major determining factors for abnormal electroencephalographic findings in HE patients and serum sodium acts as an independent risk factor for $\mathrm{HE}^{6,8}$ It has also been observed that low serum sodium levels are a very common finding in patients with hepatorenal syndrome and it may not only due to increased AVP levels but also to a markedly reduced glomerular filtration rate and increased proximal sodium reabsorption ${ }^{9}$. Severity of neurological symptoms in patients with hyponatremia correlates roughly with the levels of osmolality and sodium in the extracellular fluid. However, rather than the absolute reduction in serum sodium levels, the most important factor in determining the severity of neurological symptoms is the rate of fall in serum sodium levels ${ }^{6}$. The present study is designed to determine the correlation between serum sodium level and severity of hepatic encephalopathy. As mentioned above, the serum sodium level is a strong predictor of severity of hepatic encephalopathy and also the literature suggested a bit variation in the correlation coefficient between serum sodium level and severity of HE. This study will provide us with local statistics about the correlation and if found to significantly negatively correlated, we will share the results of the study with other local gastroenterologist and will recommend more studies on its prognostic significance before concluding its routine monitoring and baseline screening in patients with cirrhosis and $\mathrm{HE}$. 


\section{MATERIAL AND METHODS}

This study was conducted at Naseer Teaching Hospital Peshawar. Duration of the study was 01 year and the study design was cross sectional (Correlation) study in which a total of 408 patients were observed by using -0.1411 of correlation coefficient between serum sodium and hepatic encephalopathy $95 \%$ confidence level and $80 \%$ power of test. More over non probability consecutive sampling was used for sample collection. Patients presenting within 24 hours of onset of $\mathrm{HE}$ and both male and female patients aged 18 years and above were included while Patients with concomitant chronic renal failure and who are on haemodialysis patients with acute fulminant hepatitis, Patients having co morbid conditions like diabetes (fasting blood glucose of $\geq 126 \mathrm{mg} / \mathrm{dl}$ ) and hypertension (Blood Pressure of $\geq 140 / 90 \mathrm{mmHg}$ ), Patients having spontaneous bacterial peritonitis on admission were excluded. The above mentioned conditions act as confounders and had cause bias in the study results if not excluded.

This study was conducted after approval from hospital ethical and research committee. All admitted patients meeting the inclusion criteria were included in the study. The diagnosis of cirrhosis and $\mathrm{HE}$ was based on criteria mentioned above in operational definitions. The purpose and benefits of study was explained to the patients and a written informed consent was obtained. All patients were subjected to detailed history and examination. HE severity was assessed using west heaven classification for grading. From all patients $5 \mathrm{cc}$ of blood was taken under strict aseptic technique and was sent to hospital laboratory on the same day. Serum sodium level was measured under the supervision of a biochemist who has more than 10 years experience in biochemistry.

All the above mentioned information including name, age, gender and address was recorded in the study Performa. Strict exclusion criteria had followed to control confounders and bias in study results. Data collected was entered in SPSS 16. Mean \pm SD was calculated for continuous variable like age and serum sodium and categorical variable like gender was expressed as frequencies and percentages. Spearman's rank correlation coefficient was calculated to investigate the bivariate relationship between serum sodium and HE severity on west heaven system. Results were presented as tables and graphs.

\section{RESULTS}

In this study 408 patients were observed in which $126(31 \%)$ patients were in age ranged 40-50 years, $135(33 \%)$ patients were in age ranged $51-60$ years and $147(36 \%)$ patients were in age ranged $61-70$ years. Mean age was 65 years with SD \pm 0.315 . two humdred fifty three $62 \%$ patients were male whle 155(38\%) patients were female.one hundred eighty four $45 \%$ patients had serum sodium level ranged $120-125 \mathrm{meq} / \mathrm{L}, 204(50 \%)$ patients had serum sodium level ranged $126-130 \mathrm{meq} / \mathrm{L}$ and $20(5 \%)$ patients had serum sodium level ranged $131-133 \mathrm{meq} / \mathrm{L}$. Mean serum sodium level was $123 \mathrm{meq} / \mathrm{L}$ with $\mathrm{SD} \pm 0.21$. Severity of hepatic encephalopathy was measured in term of grades and was analyzed as $20(5 \%)$ patients had severity of grade I, $159(39 \%)$ patients had severity of grade II, 196(48\%) patients had severity of grade III and 33(8\%) patients had severity of grade IV. Correlation of severity of hepatic encephalopathy with serum sodium level was analyzed as all the 20 patients with severity of grade I had serum sodium level ranged 131-133 $\mathrm{meq} / \mathrm{L}$. All the 159 patients with severity of grade II had serum sodium level ranged $126-130 \mathrm{meq} / \mathrm{L}$. In 196 patients with severity of grade III, 45 patients had serum sodium level ranged $126-130 \mathrm{meq} / \mathrm{L}$ while 151 patients had serum sodium level ranged $120-125 \mathrm{meq} / \mathrm{L}$ where as all the 33 patients with severity of grade IV had serum sodium level ranged $120-125 \mathrm{meq} / \mathrm{L}$.

Table1: Age Distribution $(n=408)$ 


\begin{tabular}{|c|c|c|}
\hline AGE & FREQUENCY & PERCENTAGE \\
\hline $\mathbf{4 0 - 5 0}$ years & 126 & $31 \%$ \\
\hline $\mathbf{5 1 - 6 0}$ years & 135 & $33 \%$ \\
\hline $\mathbf{6 1 - 7 0}$ years & 147 & $36 \%$ \\
\hline Total & 408 & $100 \%$ \\
\hline
\end{tabular}

Table 2: Gender Distribution $(n=408)$

\begin{tabular}{|c|c|c|}
\hline GENDER & FREQUENCY & PERCENTAGE \\
\hline Male & 253 & $62 \%$ \\
\hline Female & 155 & $38 \%$ \\
\hline Total & 408 & $100 \%$ \\
\hline
\end{tabular}

Table 3: Serum Sodium Level $(n=408)$

\begin{tabular}{|c|c|c|}
\hline $\begin{array}{c}\text { SERUM SODIUM LEVEL } \\
\text { (MEQ/L) }\end{array}$ & FREQUENCY & PERCENTAGE \\
\hline $120-125$ & 184 & $45 \%$ \\
\hline $126-130$ & 204 & $50 \%$ \\
\hline $131-133$ & 20 & $5 \%$ \\
\hline Total & 408 & $100 \%$ \\
\hline
\end{tabular}

Mean serum sodium level was 123 with SD \pm 0.21

Table 4: Severity of Hepatic Encephalopathy $(n=408)$

\begin{tabular}{|c|c|c|}
\hline $\begin{array}{c}\text { SEVERITY OF HEPATIC } \\
\text { ENCEPHALOPATHY }\end{array}$ & FREQUENCY & PERCENTAGE \\
\hline Grade I & 20 & $5 \%$ \\
\hline Grade II & 159 & $39 \%$ \\
\hline Grade III & 196 & $48 \%$ \\
\hline Grade IV & 33 & $8 \%$ \\
\hline Total & 408 & $100 \%$ \\
\hline
\end{tabular}

Table 5: Correlation of Severity of Hepatic Encephalopathy with Serum Sodium Level $(n=408)$

\begin{tabular}{|c|c|c|c|c|c|}
\hline \multicolumn{2}{|c}{} & \multicolumn{3}{c|}{ SERUM SODIUM LEVEL } & \\
\cline { 3 - 6 } & & $120-125$ & $126-130$ & $131-133$ & Total \\
\hline \multirow{3}{*}{$\begin{array}{c}\text { SEVERITY OF HEPATIC } \\
\text { ENCEPHALOPATHY }\end{array}$} & Grade I & 0 & 0 & 20 & 20 \\
\cline { 2 - 6 } & Grade II & 0 & 159 & 0 & 159 \\
\cline { 2 - 6 } & Grade III & 151 & 45 & 0 & 196 \\
\cline { 2 - 6 } & Grade IV & 33 & 0 & 0 & 33 \\
\hline & Total & 184 & 204 & 20 & 408 \\
\hline
\end{tabular}

Spearman's rank correlation coefficient was 2.28

$P$ value was 0.0001 


\section{DISCUSSION}

Hepatic Encephalopathy has never been less than an unsolved mystery for physicians and researchers around the globe. Since the time of Hippocrates it has been difficult to diagnose and manage any patient of hepatic encephalopathy. Although the exact pathogenic mechanism is yet to be determined, modern research has proved time and again that identifying and removing precipitating factors is still the key step in the overall management. Our study shows that majority of the patients were old age was 31\% patients were in age ranged $40-50$ years, 33\% patients were in age ranged $51-60$ years and $36 \%$ patients were in age ranged $61-70$ years. Sixty two percent patients were male and $38 \%$ patients were female. Similar results were found in other study in which majority (86\%) of patients were more than forty years old. Sheikh S et al ${ }^{141}$ had a similar finding in the province of Balochistan. Slight male dominance in progression to advanced stages of chronic liver disease was found in our patients. In our study correlation of severity of hepatic encephalopathy with serum sodium level was analyzed as all the 20 patients with severity of grade I had serum sodium level ranged $131-133 \mathrm{meq} / \mathrm{L}$. All the 159 patients with severity of grade II had serum sodium level ranged $126-130 \mathrm{meq} / \mathrm{L}$. In 196 patients with severity of grade III, 45 patients had serum sodium level ranged $126-130$ meq/L while 151 patients had serum sodium level ranged $120-125 \mathrm{meq} / \mathrm{L}$ where as all the 33 patients with severity of grade IV had serum sodium level ranged 120-125 meq/L. Spearman's rank correlation coefficient was -0.28 . Similar results were found in done by Sanyal $A$ et al ${ }^{10}$ as he reported correlation between serum sodium level and severity of $\mathrm{HE}$ is -0.5830 . Montono LA et al ${ }^{11}$ had reported correlation of serum sodium level and severity of $\mathrm{HE}$ as -0.14 . Serum sodium predicts prognosis in cirrhosis and may improve the prognostic accuracy of the model for end stage liver disease (MELD) score, but the available information is limited $^{12}$.

Saad $M$ et al ${ }^{13}$ had reported that patients with low serum sodium tend to have more severe ascites $(p=0.001)$. Hepatic encephalopathy was more frequent in patients with serum sodium $<130$ $\mathrm{meq} / \mathrm{l}(\mathrm{p}=0.001)$. In another study conducted by Cardenas et al ${ }^{14}$ shows that more than one half $(57.9 \%)$ of patients had values of serum sodium concentration below the normal range $(<135 \mathrm{meq} / \mathrm{l})$ and $30.7 \%$ had values $<130 \mathrm{meq} / \mathrm{l}$. Low serum sodium levels were more frequent in patients with severe liver failure (Child-Pugh class $\mathrm{C}$ ) irrespective of age and gender of the patient. The frequency of serum sodium $<130 \mathrm{mmol} / \mathrm{L}$ in these patients is in accordance with a study by Borroni et al. ${ }^{15}$ who reported hyponatraemia in $30 \%$ of cases. In a Pakistani study it was found to be $26.7 \% .{ }^{13}$ The prevalence of $\mathrm{HE}$ was greater $(34.15 \%)$ as compared to other national and international studies. The patients with serum sodium < $130 \mathrm{meq} / \mathrm{l}$ had a significantly greater frequency $(64 \%)$ of $\mathrm{HE}$. Many of them had grade III-IV HE as compared to patients with normal serum sodium concentration. In previous studies, internationally as well as in Pakistan, there is correlation between hyponatremia and presence of HE, but this is even more highlighted in this study. The relationship between hepatic encephalopathy and serum levels may be explained on the basis of more severe liver failure among patients with serum sodium < $130 \mathrm{meq} / \mathrm{l}$, and the possibility that the two events may be pathophysiologically linked. ${ }^{16}$ Low serum sodium levels in patients with cirrhosis are associated with a remarkable reduction in the cerebral concentration of organic osmolytes that probably reflect compensatory osmoregulatory mechanisms against cell swelling. ${ }^{17,18,19}$ A major advance in our ability to treat hyponatremia is the introduction and approval of aquaretics (vaptans) which are vasopressin V2-receptor antagonists. ${ }^{20}$ In a review of a previously conducted multi-center study in overseas countries, 997 patients with liver cirrhosis and concurrent ascites, who were under the care of hepatologists in hepatology outpatient clinics, were assigned to three groups based on serum sodium concentration, in a manner similar to that of the current study. The prevalence of hyponatremia at a serum sodium $\leq 135 \mathrm{mmol} / \mathrm{L}$ was $49.4 \%$. Concurrent complications such as severe ascites, impaired renal function, hepatic encephalopathy, spontaneous bacterial peritonitis and hepatorenal syndome, except for gastrointestinal bleeding, occurred with a higher probability in 
cases of severe hyponatremia (serum sodium $\leq 130 \mathrm{mmol} / \mathrm{L}$ ) ${ }^{21}$. In a study with 156 patients hospitalized with liver cirrhosis, the prevalence of hyponatremia, based on a serum sodium concentration $\leq 130 \mathrm{mmol} / \mathrm{L}$, was $29.8 \%$, and hyponatremia was significantly correlated with infection and ascites ${ }^{22}$. In the another study, conducted in patients hospitalized with complications due to liver cirrhosis, the prevalence of hyponatremia at a serum sodium concentration $\leq 135 \mathrm{mmol} / \mathrm{L}$ was $47.9 \%$, and that of severe hyponatremia at a serum sodium concentration $\leq 130 \mathrm{mmol} / \mathrm{L}$ was $27.1 \%$. These results were similar to the overseas reports. In fact, the severity of hyponatremia, particularly at serum sodium concentrations $\leq 130 \mathrm{mmol} / \mathrm{L}$, corresponded to higher risks for developing ascite encephalopathy, spontaneous bacterial peritonitis, hepatic hydrothorax, severe ascites, and severe hepatic encephalopathy, compared with the risks in patients with a serum sodium $\geq 136 \mathrm{mmol} / \mathrm{L}$. In agreement with previous reports, serum sodium concentration was not associated with the presence of varices. Furthermore, there was no significant difference in the incidences of hepatorenal syndrome and bacterial infections, except for spontaneous bacterial peritonitis, among the three serum sodium concentration groups. It is possible that no significance was found owing to a lack of statistical power based on the small number of patients with hepatorenal syndrome $(n=6)$ or infection $(n=15)$.

Currently, many ongoing studies are examining the pathophysiology of hyponatremia accompanied by liver cirrhosis, and delusional hyponatremia has been considered the most plausible pathophysiology. ${ }^{23}$ In animal experiments where portal hypertension was induced, the concentration of nitric oxide (NO), with its powerful vasodilatory action, was increased; NO is also increased in patients with portal hypertension. Owing to the vasodilatory effect of increased NO and the lower effective circulating blood volume in these patients, anti-diuretic hormone secretion is facilitated with the mediation of bar receptors, despite the presence of a hypo-osmotic environment. The increased level of anti-diuretic hormones lowers solute-free water excretion, leading to dilutional hyponatremia. In the current study, the risks for complications such as severe as cites, spontaneous bacterial peritonitis, hepatic hydrothorax, and hepatic encephalopathy were increased at low serum sodium concentrations. With the exception of hepatic encephalopathy, these complications are believed to occur because of increased body fluid resulting from the impairment of solute-free water excretion. Hepatic encephalopathy occurs as a result of severe hepatic dysfunction. In cases in which hyponatremia is concurrently present, however, the increased intracellular concentration of glutamine due to hyperammonemia, along with the adaptation to the hypoosmotic extracellular environment of hyponatremia, increases the severity of hepatic encephalopathy, because organic osmolytes such as myo-inositol become further depleted in the cells. ${ }^{24}$ The pathophysiology of hepatorenal syndrome can also be explained by increased body fluid resulting from the impairment of solute-free water excretion.

As mentioned earlier, however, our results did not reach statistical significance, probably because only a few patients with hepatorenal syndrome were enrolled in the present study, in contrast to other studies ${ }^{25}$ In some studies severity of varices did not correlate with serum sodium concentration because development of varices depends on not the excess of body water but the histological changes such as the compression of venules by regenerating nodules, perisinusoidal obstruction resulting from per portal inflammation, or fibrosis and decreased sinusoidal elasticity and diameter caused by collagen deposition in the space of Disse. Further studies are needed to demonstrate a significant relationship between the serum sodium concentration and the above histological changes. MELD scores were initially designed to predict survival in patients who underwent elective placement of a transjugular intrahepatic portosystemic shunt and are currently used as an indicator of mortality in patients with liver cirrhosis ${ }^{26}$ MELD scores are advantageous for objectively predicting mortality in a homogeneous manner because their constituent variables are objective. However, MELD scores have the disadvantage of not reflecting the early deaths in patients with lower MELD scores. Many studies have been conducted recently to examine the 
clinical usefulness of MELD-Na scores using the serum sodium concentration as a prognostic indicator. In the clinical setting, MELD-Na scores may be more useful than MELD scores for the allocation of livers for transplantation and for the prediction a short-term death. ${ }^{27}$ The clinical significance of the serum sodium concentration was demonstrated in a retrospective study that looked for factors associated with death prior to liver transplantation in 507 patients with liver cirrhosis and lower initial MELD scores. The persistent presence of ascites and hyponatremia were independent risk factors in patients with MELD scores lower than 21 points, and MELD scores were a prognostic indicator only in other patients. ${ }^{28,29}$ In the current study, there was a significant difference in the 3-year survival rate among the three serum sodium concentration groups. However, the 3-year survival rate was higher in patients with serum sodium concentration $\leq 130$ $\mathrm{mmol} / \mathrm{L}$ than in those with serum sodium concentration between 131 and $135 \mathrm{mmol} / \mathrm{L}$. These results indicate that the serum sodium concentration alone cannot predict the survival rate in patients with liver cirrhosis and that factors other than the serum sodium concentration affect patient survival. Further large-scale studies are warranted to explore these factors.

\section{CONCLUSION}

Hyponatremia was a common feature in patients with cirrhosis and its severity increased with the severity of liver disease. The existence of serum sodium concentration $<135 \mathrm{mmol} / \mathrm{L}$ was associated with greater frequency of hepatic encephalopathy. It was also noticed that more severe the hyponatremia, greater will be the grade of hepatic encephalopathy. Close monitoring of serum sodium concentration should be performed in patients with cirrhosis in order to prevent the rapid development of cirrhosis related complications.

\section{REFRENCES}

1. Nazish Z, Inayatullah M, Nasir SA, Arshad M, Tanveer S, Naqvi AB. Liver cirrhosis; clinical presentation. Professional Med J 2002; (3):207-12.

2. Haussinger D, Kircheis G. Hepatic encephalopathy. Schweiz Rundsch Med Prax May 2002; 91(22): 957-63.

3. Riordan SM, Williams R. Treatment of hepatic encephalopathy. N Eng J Med 1997; 337(7):473-9.

4. Caruntu FA, Benea L. Spontaneous bacterial peritonitis: pathogenesis, diagnosis, treatment. J Gastrointestin Liver Dis 2006;15(1):51-6.

5. Rimola A, Garcia-Tsao G, Navasa M. Diagnosis, treatment and prophylaxis of spontaneous bacteria! peritonitis: a consensus document. J Hepatol 2000;32:142-53.

6. Strauss E, Caly WR. Spontaneous bacterial peritonitis: a therapeutic update. Expert Rev Anti Infect Ther 2006;4(2):249-60.

7. Iqbal S, Iman NU, Alam N, Rahman SU. Incidence of Spontaneous bacterial peritonitis in Liver cirrhosis, the causative organisms and antibiotic sensitivity. J Post grad Med Inst 2004;18(4):614-9.

8. Sheer TA, Runyon BA. Spontaneous bacterial peritonitis. Dig Dis 2005;23(1):39-46.

9. Mashud I, Khan $H$, Khattak $A M$. Relative frequency of Hepatitis $B$ and $C$ viruses in patients with hepatic cirrhosis at DHQ Teaching Hospital DI Khan. J Ayub Med Coll Abbottabad 2004;16(1):32-4.

10. Sanyal A, Younossi ZM, Bass NM, Mullen KD, Poordad F, Brown RS et al. Randomised clinical trial: rifaximin improves health-related quality of life in cirrhotic patients with hepatic encephalopathy a double-blind placebo-controlled study. Aliment Pharmacol Ther. 2011;34(8):853-61.

11. Montano-Loza A, Meza-Junco J, Prado CM, Lieffers JR, Baracos VE, Bain VG et al. Muscle Wasting Is Associated With Mortality in Patients With Cirrhosis. Clin Gastroenterol Hepatol.2012;10(2):16673. 
12. Londoño M, Cárdenas A, Guevara M, Quintó L, Heras $D$, Navasa $M$ et al. MELD score and serum sodium in the prediction of survival of patients with cirrhosis awaiting liver transplantation. Gut. 2007;56(9):1283-90.

13. Saad M, Saleem A, lqbal A. Precipitating factors of hepatic encephalopathy experience at Pakistan Insitute of Medical sciences Islamabad; J Ayub med coll Abbottabad. 2006;18(4)57-61.

14. Cárdenas A, Ginès P. Predicting mortality in cirrhosis-serum sodium helps. N Engl J Med 2008; 359:1060-6.

15. Borroni G, Maggi A, Sangiovanni A, Cazzaniga M, Salerno F. Clinical relevance of hyponatremia for the hospital outcome of cirrhotic patients. Dig Liver Dis 2000;32:605-10.

16. Angeli $P$, Wong $F$, Watson $H$, Gines $P$. Hyponatremia in cirrhosis: results of a patient population survey. Hepatology 2006;44:1535-42.

17. Haussinger D, Laubenberger J, Vom Dahl S, Ernst T, Bayer S, Langer M, et al. Proton magnetic resonance spectroscopy studies on human brain myo-inositol in hypo-osmolarity and hepatic encephalopathy. Gastroenterology 1994;107:1475-80.

18. Restuccia T, Gomez-Anson B, Guevara M, Alessandria C, Torre A, Alayrach ME. Effects of dilutional hyponatremia on brain organic osmolytes and water content in patients with cirrhosis. Hepatology 2004;39:1613-22.

19. Ha"ussinger D. Low grade cerebral edema and the pathogenesis of hepatic encephalopathy in cirrhosis. Hepatology 2006;43:1187-90.

20. Elhassan EA, Schrier RW. Hyponatremia: diagnosis, complications, and management including V2 receptor antagonists. Curr Opin Nephrol Hypertens 2011;20:161-8.

21. Conn HO. Effects of high-normal and low-normal serum potassium levels on hepatic encephalopathy: facts, half-facts or artifects? Hepatology 1994;20:1637.

22. Hazell AS, Butterworth RF. Hepatic encephalopathy: an update of pathophysiologic mechanism. Proc. Soc. Exp. Biol. Med. 1999;222:99.

23. Cordoba J.Blei AT. Treatment of hepatic encephalopathy. Am. J. Gastroenterol. 1997;92:1429

24. Durrani $A B$, Rana $A B$ Siddiqi HS, Marwat BU. The spectrum of chronic liver disease in Balochistan. JCPSP 2001;11(2):95-7.

25. Alam I, Razaullah, Haider I, Hamayun M, Taqweem A, Nisar M. Spectrum of precipitating factors of hepatic encephalopathy in liver cirrhosis. Pakistan J.Med. Res. 2005;44(2):96-100.

26. Bustamante J, Rimola A, Ventura PJ, Navasa M, Cirera I, Reggiardo V et al. Prognostic significance of hepatic encephalopathy in patients with cirrhosis. J Hepatol. 1999;30:890-95.

27. Shiekh S. Portal systemic encephalopathy in cirrhotic liver disease. Experience at People Medical College, Nawabshah. J Coll Physican Surg Pak 1998;8:53.

28. Ahmed H, Rehman MU, Saeedi I, Shah D. Factors precipitating hepatic encephalopathy in cirrhosis liver. Postgrad Med Inst 2001;15(1):91-7.

29. Khurram M, Khaar HB, Minhas Z, Javed S, Hassan Z, Hameed TA et al. An experience of cirrhotic hepatic encephalopathy at DHQ teaching hospital. J Rawal Med Coll 2001;5:60. 